\title{
WHY SHOULD WE PUBLISH IN JOURNALS INDEXED IN WEB OF SCIENCE?
}

\author{
Milan Kubiatko \\ Masaryk University in Brno, Czech Republic
}

I would like to thank the editor of the journal, who offered me to write an editorial. When I was thinking about the topic, which would be interesting for the readers of journals, I got more ideas. One of the topics, which is more and more discussed is the problem of publication. Where should the author send his manuscript? He/she should choose a shorter way or try to send his own manuscript to the journal with the demanding reviewing process. But, the author is the person who makes the final decision, our effort is to evoke only thinking about the importance of academic work.

What is better? An article in Science or an article in Multidisciplinary Journal of Science Education and Magnetic Resonance. I think, the majority of people will say "Science". But I think it is a very hard question and it is demanding an answer to it. Why? Because, to publish an article in a prestige journal, like Science is, it is a very long way with many stops. The author(s) of future articles have to communicate with an editor about the suitability, originality, potential readability, intelligibility, potential citations and other factors, which can make your future article appropriate for the journal. And then the right review process will begin. The journals include and also those, who would like to be included in the Web of Science, would try to keep some (unwritten) conditions. Some of them are obvious, for example, wide editorial boards composed of the experts blind reviews without any favoritism of some authors, the language having to be only English and others. However, any journal included in the Web of Science has to endeavor to stay there, because WoS still is observing, if the journal keeps the conditions. If not, it is excluded from the database and we can say it was a destiny of many journals. And the way back is very demanding. So, the behavior of the majority of the journals included in the WoS is very careful, it is aiming to demanding review process and the editor(s) are trying to keep possibilities to publish in journals for every author similar. On the other side, the journals out of databases have got a little bit different behavior. The time length from sending a manuscript till publication in the issue is shorter in comparison with the time length in the journals in WoS. Then the language in many cases is the language of the country, where the journal is printed out. Toward this fact, there will be a short information about a couple of lines below. Next, the periodicity of the authors, one author can publish in a journal more than one or two times per year. And there are many other features like "friendly" review, editorial board from one institution, etc. But, all these aspects are not negative, as it can seem. Because not every journal has got international expectations and it wants to be indexed in any world database, like WoS or SCOPUS and the interest of local authors writing in the native language is sufficient. The unindexed journals have justification for the local purposes. The worse situation is, when the principals of journals deny higher importance and impact of international journals. So, this fact can lead to degradation of the field of study. This is only a very brief statement, which is ongoing in many faculties and universities all over the world and that's a very long discussion.

So, why it is better to publish in journals indexed in the recognized databases? And which databases are the most recognized? Toward the second question, it is possible to find many articles, which focus on the comparison of different database importance (e.g. Falagas et al. 2008). From these analyses, it is possible to find out that the most valuable databases are WoS and SCOPUS. From the simple view, these databases are gathering the most respected journals from all over the world, but I think, it is useless to write a more detailed information about the importance of these databases, because the prerequisite is, that every researcher knows these facts. Only a brief information toward the answer to the first question. The journal selection process in WoS has been applied 
consistently for more than 45 years. Every journal included in the WoS has been evaluated according to the highest standards, which were originally defined by Eugene Garfield, the founder and president Emeritus of ISI. This steady application of the quality has enabled a continuous development of the WoS, whose primary purpose is to provide comprehensive coverage of the world's most important and influential scholarly journals (Testa, 2006). The important fact is also an international impact on the authors' work. The presence of an international base of the authors and editors is a good indicator of the health of a journal and a predictor of its ability to continue to publish important research in the future (Testa, 2006). The next key point is citation analysis, the citations are very important in the researchers' work, because the citations are a mirror of importance, interest and potential of the article. As WoS so SCOPUS offer citation report of articles and authors too. As Testa (2006) wrote, an authoritative citation analysis is a key factor in the evaluation of journals, because all cited references to articles in both covered and non-covered articles are captured in order to measure the importance, influence, and overall usefulness of a journal. The other importance of citations is that they can be used as a basis for making policy decisions. For instance, there has been a proposal in UK that research institutions should be funded based on their research performance as reflected through bibliometric indicators (Hobbs, Stewart 2006). Another reason why citations are important is that they are used to rank journals based on the ISI impact factor and can also be a useful tool for establishing a relationship between papers, fields, authors or even journals (Jusoff, 2008).

So, as it is possible to see, to publish in the journal, included in any international database is important and useful for the authors and also for the institution, because it is a big prestige to have an article in this kind of journal. Because the reject rate in these journals is very high, the journals publish only original, interesting articles with the potential to be cited.

\section{References}

Falagas, M. E., Pitsouni, E. I., Malietzis, G. A., Pappas, G. (2008). Comparison of Pub Med, Scopus, Web of Science, and Google Scholar: Strengths and weaknesses. The Journal of the Federation of American Societies for Experimental Biology, 22 (2), 338-342.

Hobbs, F. D., Stewart, P. M. (2006). How should we rate research? British Medical Journal, 332 (7548), 983-984.

Jusoff, H. K. (2008). In search of best impact and citation indexed journals towards achieving goals of universities. Journal of Biochemical Technology, 1 (1), 23-29.

Testa, J. (2006). The Thomson Scientific journal selection process. International Microbiology, 9 (2), 135-138.

Milan Kubiatko 